\title{
Trade-Offs in Fairness and Preference Judgments
}

Lisa D. Ordoñez

Barbara A. Mellers

University of Pennsylvania

Follow this and additional works at: https://repository.upenn.edu/marketing_papers

Part of the Behavioral Economics Commons, Cognitive Psychology Commons, Economic Theory Commons, Income Distribution Commons, Marketing Commons, and the Public Economics Commons

Recommended Citation (OVERRIDE)

Mellers, B.A. \& Ordoñez, L.D. (1993). Trade-Offs in Fairness and Preference Judgments. In Psychological Perspectives on Justic: Theory and Application, 138-154. Cambridge University Press.

This paper is posted at ScholarlyCommons. https://repository.upenn.edu/marketing_papers/393

For more information, please contact repository@pobox.upenn.edu. 


\title{
Trade-Offs in Fairness and Preference Judgments
}

\author{
Abstract \\ At the heart of many debates about distributive justice is the widely assumed trade-off between equality \\ and efficiency (Okun, 1975). In the present chapter, equality refers to the distribution of income within a \\ society. Equality increases whenever income variability is reduced. Efficiency refers to the goods and \\ services that result from a given input - production, physical capital, or human labor. Efficiency increases \\ whenever society produces more from the same input. Trade-offs between equality and efficiency occur \\ because increases in one often lead to decreases in the other. An egalitarian society satisfies basic needs \\ by establishing programs that redistribute wealth. But those programs can reduce efficiency when they \\ introduce bureaucratic waste or diminish financial incentives. A reduction in efficiency can lead to fewer \\ investments, fewer jobs, and declining productivity.

\section{Disciplines} \\ Behavioral Economics | Business | Cognitive Psychology | Economic Theory | Income Distribution | \\ Marketing | Public Economics
}




\title{
7 Trade-offs in fairness and preference judgments
}

\author{
Lisa D. Ordóñez and Barbara A. Mellers
}

At the heart of many debates about distributive justice is the widely assumed trade-off between equality and efficiency (Okun, 1975). In the present chapter, equality refers to the distribution of income within a society. Equality increases whenever income variability is reduced. Efficiency refers to the goods and services that result from a given input - production, physical capital, or human labor. Efficiency increases whenever society produces more from the same input. Trade-offs between equality and efficiency occur because increases in one often lead to decreases in the other. An egalitarian society satisfies basic needs by establishing programs that redistribute wealth. But those programs can reduce efficiency when they introduce bureaucratic waste or diminish financial incentives. A reduction in efficiency can lead to fewer investments, fewer jobs, and declining productivity.

\section{Theories of distributive justice}

Is there an ideal point along the equality-efficiency continuum? Political and moral philosophers have articulated a number of positions about what constitutes justice and how to arrive at just distributions of resources and rewards. These positions place differential emphasis on equality and efficiency.

Utilitarians believe that society should be arranged to maximize the total (or sometimes average) utility of all individuals (Bentham, 1961/1789). If utility is identical to profit, then profit maximization occurs when efficiency

We thank Jon Baron, Karen Biagini, Michael Birnbaum, John Carroll, Shi-jie Chang, Alan Cooke, Robyn Dawes, and Philip Tetlock for helpful discussions and comments on drafts of this chapter. We also thank Kim Gallegus and Katty Ho for help with data collection. This research was supported by an NSF grant (BNS-90-16526) to the first author and another NSF grant (SES-89-08698) to the second author. The first author was also supported by a Ford Foundation Predoctoral Fellowship (880-0765). 
is greatest. This version of utilitarianism might emphasize efficiency over equality. On the other hand, if utility is a negatively accelerated function of income, the poor benefit more from any given dollar. This form of utilitarianism might strike a compromise between equality and efficiency in an attempt to provide both assistance at the bottom and incentives at the top.

Egalitarians argue that society should be arranged to provide food, shelter, and essential medical care for all concerned. These basic needs are satisfied by means of redistributive policies that minimize income inequality. In this framework, the emphasis is on equality rather than efficiency.

More recently, Rawls (1971) developed a philosophical theory of justice based on a social contract. Rawls asks what would happen if the framers of society operated behind a "veil of ignorance," so that they knew nothing about their future socioeconomic position. Rawls contends that two principles of justice would emerge. The first is the principle of greatest equal liberty; each person would have an equal right to the most extensive system of liberties and freedoms. The second is the difference principle, which asserts that societal and economic institutions should be arranged to benefit the worst off. This principle is a maximin rule. Disparities in wealth are assumed to be just when they improve the welfare of the poorest members of society. This theory focuses on the incomes of the least advantaged members of society.

\section{Compromises between equality and efficiency}

Researchers have posited that, for an assortment of cognitive and political reasons, people have difficulty making trade-offs between strongly held values such as environmental protection and economic growth (Abelson \& Levi, 1985; Einhorn \& Hogarth, 1981; Tetlock, 1986). Hadari (1988) notes that some philosophical theories of distributive justice structure society to avoid trade-offs between basic values. Utilitarians escape trade-offs by reducing all values to a single scale of utility or welfare. Rawls avoids tradeoffs by lexicographically ordering values. Only after a society has established basic liberties for everyone does the maximin rule apply.

The present chapter investigates how people make trade-offs when judging societal fairness and preference. It builds on earlier work by Mitchell, Tetlock, Mellers, and Ordónez (1992) that examined the judged fairness of hypothetical societies. In those experiments, societies were displayed as income distributions, that is, average incomes in each quartile. Equality and efficiency were manipulated using income variance and average income, respectively. Societies with more income variance had greater income inequality. Societies with higher average income had greater efficiency. Subjects were told to assume that the distribution of inputs was held constant across all societies, so greater profits resulted from greater efficiency.

A fairness ranking over societies was derived for each individual. When 
the effort-reward correlation was low, rankings correlated higher with income variance (equality). When the effort-reward correlation was high, rankings were better predicted from average income (efficiency). Mitchell et al. (1992) concluded that the effort-reward correlation or level of meritocracy was a moderator of equality-efficiency trade-offs.

In Mitchell et al. (1992), income variance was confounded with minimum income (i.e., average income in the lowest quartile). We manipulate both factors and investigate whether the predictability of income variance is due to a concern for the overall income variability or the floor of the income distribution. Furthermore, we manipulate the effort-reward correlation in such a way that subjects can make trade-offs between this factor and others. We also investigate judged preferences to examine whether people prefer to live in societies they judge more fair. Finally, do trade-offs made at the societal level also occur at the individual level? We ask subjects to judge the extent to which an individual within different societies is overbenefited or underbenefited. Of interest is whether the same factors influence fairness judgments at the micro and macro levels (Brickman, Folger, Goode, \& Schul, 1981).

\section{Macro fairness and preference}

Two experiments examined judgments of societal fairness and preference. Societies were displayed as scatterplots with salary plotted against work index. Work index, ranging from 0 (lowest contribution) to 4 (highest contribution), was said to reflect merit, seniority, effort, productivity, experience, etc. The distribution of work was held constant across societies.

In Experiment 1, eight societies were constructed from variations along three factors: minimum salary, mean salary, and salary standard deviation. ${ }^{1}$ Figure 1 presents two societies that differ in salary mean and salary standard deviation. Society $A$ has a lower mean salary, but less salary variability; Society B has a higher mean salary, but more salary variability.

In Experiment 2, sixteen societies were formed by manipulating the three factors in Experiment 1 and the effort-reward correlation. Figure 2 shows two societies that differ in correlation and minimum salary. Society A has a higher minimum salary but a lower work-salary correlation, and Society $B$ has a higher correlation but a lower minimum salary.

Table 1 gives information about the eight societies in Experiment 1. The correlation between work and salary ranged from .19 to .77 across societies. Table 2 provides information about the sixteen societies in Experiment 2. In both experiments, the distribution of work was held constant.

Subjects were presented with all possible pairs of societies. In the fairness conditions, subjects judged which society was more fair. In the preference conditions, subjects selected the society in which they preferred to live. Subjects were told that the poverty level was $\$ 15,000 .^{2}$ After comple- 


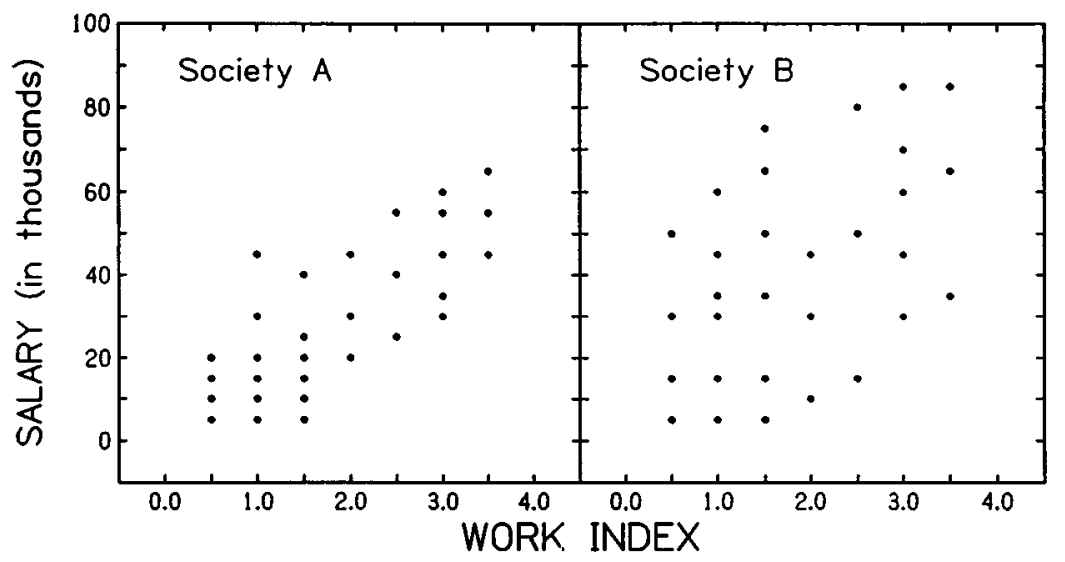

Figure 1 Trade-offs between measures of equality and efficiency in Experiment 1. Society A has a narrow salary standard deviation and a low mean salary. Society B has a wide salary standard deviation and a high mean salary.

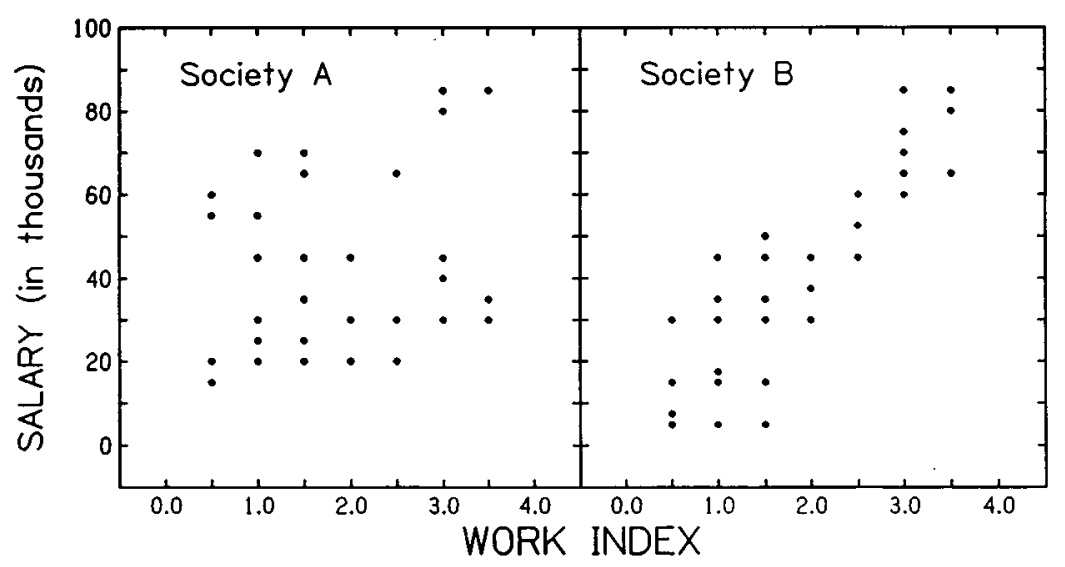

Figure 2 Correlation and minimum salary trade-offs in Experiment 2. Society A has a high minimum salary but a low correlation, and Society $B$ has a high correlation but a low minimum salary.

tion of the two tasks, subjects answered a questionnaire requesting information about sex, socioeconomic status, political party affiliation, and political views (rating on a seven-point conservative/liberal scale). In Experiment 2, subjects were also asked to state their anticipated socioeconomic status and rank the importance of each experimental factor in their fairness and preference judgments. Participants were undergraduates at the University of California at Berkeley who received credit in a lower division psychology course. There were 80 and 70 subjects in Experiments 1 and 2, respectively. 
Table 1 Societies in Experiment 1 (in thousands)

\begin{tabular}{llll}
\hline \hline Society & $\begin{array}{l}\text { Minimum } \\
\text { salary }\end{array}$ & $\begin{array}{l}\text { Mean } \\
\text { salary }\end{array}$ & $\begin{array}{l}\text { Salary } \\
\text { std. dev. }\end{array}$ \\
\hline LLW & 5 & 31 & 23 \\
LLN & 5 & 30 & 18 \\
LHW & 5 & 41 & 25 \\
LHN & 5 & 40 & 18 \\
HLW & 15 & 34 & 19 \\
HLN & 15 & 33 & 12 \\
HHW & 15 & 43 & 21 \\
HHN & 15 & 42 & 18 \\
\hline \hline
\end{tabular}

Note: The first letter in the society label refers to the minimum salary ( $\mathrm{L}=$ low and $\mathrm{H}=$ high). The second represents mean salary $(\mathrm{L}=$ low and $\mathrm{H}=$ high). The third letter refers to the salary standard deviation $(\mathrm{W}=$ wide and $\mathrm{N}=$ narrow).

Table 2 Societies in Experiment 2 (in thousands)

\begin{tabular}{lllll}
\hline \hline Society & Correlation & $\begin{array}{l}\text { Minimum } \\
\text { salary }\end{array}$ & $\begin{array}{l}\text { Mean } \\
\text { salary }\end{array}$ & $\begin{array}{l}\text { Salary } \\
\text { std. dev. }\end{array}$ \\
\hline LLLW & 0.22 & 5 & 31 & 23 \\
LLLN & 0.27 & 5 & 30 & 18 \\
LLHW & 0.19 & 5 & 41 & 25 \\
LLHN & 0.25 & 5 & 40 & 18 \\
LHLW & 0.19 & 15 & 34 & 19 \\
LHLN & 0.21 & 15 & 33 & 12 \\
LHHW & 0.22 & 15 & 43 & 21 \\
LHHN & 0.18 & 15 & 42 & 18 \\
HLLW & 0.87 & 5 & 31 & 23 \\
HLLN & 0.79 & 5 & 30 & 18 \\
HLHW & 0.87 & 5 & 41 & 25 \\
HLHN & 0.83 & 5 & 40 & 18 \\
HHLW & 0.79 & 15 & 34 & 19 \\
HHLN & 0.88 & 15 & 33 & 12 \\
HHHW & 0.87 & 15 & 43 & 21 \\
HHHN & 0.86 & 15 & 42 & 18 \\
\hline \hline
\end{tabular}

Note: The first letter in the society label refers to the correlation between work index and salary ( $\mathrm{L}=$ low and $\mathrm{H}=$ high). The second represents minimum salary ( $\mathrm{L}=$ low and $\mathrm{H}=$ high). The third letter refers to the mean salary ( $\mathrm{L}=$ low and $\mathrm{H}=$ high). The fourth represents standard deviation $(\mathrm{W}=$ wide and $\mathrm{N}=$ narrow). 


\section{Did subjects make trade-offs?}

For each subject, two societal rankings were derived - one for fairness and one for preference. These rankings were computed by counting the number of times a society was judged as more fair (or more preferred) than the others. Scores could range from 0 to 7 in Experiment 1 and from 0 to 15 in Experiment 2. The higher the score, the higher the rank of that society. If two or more societies received the same score, ranks were tied.

Trade-offs were assumed to occur if societal rankings were inconsistent with a lexicographic order of any of the experimental measures. For example, a lexicographic order of minimum salary would be one in which all societies with high minimum salaries were ranked above those with low minimum salaries. Societies with the same minimum salary might be distinguished on the basis of other factors, but this ordering would be secondary to considerations of minimum salary.

In Experiment 1,57\% and 52\% of the subjects had fairness and preference rankings that were inconsistent with any of the lexicographic orders. In Experiment 2, 38\% and 70\% had fairness and preference rankings that were inconsistent with the lexicographic orders. These subjects appeared to make trade-offs.

It could be argued that these percentages are too high, since they do not allow for error or unreliability in the data. Therefore, subjects whose rankings were almost consistent with a lexicographic order were reclassified. Whenever a subject's ranking was consistent with a lexicographic order after the ranks for two societies were reversed, that subject was assigned to the lexicographic group. With this revised count, $40 \%$ and $39 \%$ of the subjects in Experiment 1 had fairness and preference rankings that were inconsistent with lexicographic orders. In Experiment 2, 29\% and 60\% had fairness and preference rankings that were inconsistent with lexicographic orders. Thus, an average of $42 \%$ of the subjects in each condition appeared to make trade-offs.

\section{Which factors accounted for the most variance?}

Individual fairness and preference rankings were correlated with three orthogonal rankings, each based on the experimental measures (i.e., low and high mean salary, low and high minimum salary, or wide and narrow salary standard deviation). Table 3 shows the percentage of individuals whose rankings correlated highest with each experimental measure. In the fairness condition, the largest percentage of subjects had rankings that correlated highest with salary standard deviation. In the preference condition, the largest percentage of subjects had rankings that correlated highest with minimum salary. However, the most striking result in Table 3 is that there are no clear winners. Subjects used a variety of different strategies in their judgments. 
Table 3 Percentage of subjects best fit by experimental measures

\begin{tabular}{llll}
\hline \hline Response & Minimum salary & Salary std. dev. & Mean salary \\
\hline Fairness & 34 & 41 & 25 \\
Preference & 43 & 28 & 30 \\
\hline
\end{tabular}

Table 4 Median correlations of subject rankings with experimental measures shown for subject groups

\begin{tabular}{|c|c|c|c|c|c|c|}
\hline \multirow[b]{2}{*}{ Measures } & \multicolumn{3}{|c|}{ Fairness groups } & \multicolumn{3}{|c|}{ Preference groups } \\
\hline & $\begin{array}{l}\text { Minimum } \\
\text { salary }\end{array}$ & $\begin{array}{l}\text { Salary } \\
\text { std. dev. }\end{array}$ & $\begin{array}{l}\text { Mean } \\
\text { salary }\end{array}$ & $\begin{array}{l}\text { Minimum } \\
\text { salary }\end{array}$ & $\begin{array}{l}\text { Salary } \\
\text { std. dev. }\end{array}$ & $\begin{array}{l}\text { Mean } \\
\text { salary }\end{array}$ \\
\hline $\begin{array}{l}\text { Minimum } \\
\text { salary }\end{array}$ & 0.82 & 0.22 & 0.38 & 0.77 & 0.11 & 0.36 \\
\hline $\begin{array}{l}\text { Salary } \\
\text { std. dev. }\end{array}$ & 0.28 & 0.77 & 0.44 & 0.22 & 0.72 & 0.33 \\
\hline $\begin{array}{l}\text { Mean } \\
\text { salary }\end{array}$ & 0.35 & 0.28 & 0.66 & 0.44 & 0.44 & 0.78 \\
\hline
\end{tabular}

Table 4 provides information about the average correlations of subjects in each of the three groups and additional information about the extent to which their rankings correlate with other measures. Rows are the three experimental measures, and columns are the three groups of subjects whose fairness and preference rankings correlated highest with each experimental measure. Entries are median correlations. Correlations should be high down the diagonals, since subjects in those groups had rankings that were bestfit by that measure. Those correlations ranged from .66 to .82 for fairness and .72 to .78 for preference. ${ }^{3}$

Correlations on the off-diagonals show average predictability of the measures. These correlations are lower than those on the diagonals, ranging from .22 to .44 for fairness and .11 to .44 for preference. Although they are considerably smaller, these off-diagonal correlations differ significantly from zero. In sum, other factors also contribute to the predictability of the rankings.

How do societal rankings differ across the three groups? Figure 3 presents median fairness rankings for subjects in each best-fitting group. Numbers range from 1 (least fair society) to 8 (most fair society). In each box, rows are salary means, and columns are salary standard deviations. A box represents a set of societies with the same minimum salary; different boxes show societies with different minimum salaries. 
Upper boxes, center boxes, and lower boxes present median rankings for the mean salary, the salary standard deviation, and the minimum salary group, respectively. Rankings differ considerably across groups. Subjects whose rankings were best fit by mean salary assigned lower ranks to low-mean societies and higher ranks to high-mean societies. Subjects whose rankings were best fit by salary standard deviation assigned lower ranks to wide-standard-deviation societies and higher ranks to narrow-standarddeviation societies. Finally, subjects whose rankings were best fit by minimum salary tended to assign lower ranks to low-minimum-salary societies and higher ranks to high-minimum-salary societies.

Despite these differences, certain patterns are common across all three groups. Within a box, the low-mean, wide-standard-deviation society is always ranked lowest. Furthermore, the high-mean, narrow-standarddeviation society is always ranked highest. Of interest are the rankings in the other two cells. Subjects whose rankings were best predicted by salary mean (upper boxes) judged the high-mean, wide-standard-deviation society as more fair than the low-mean, narrow-standard-deviation society for both levels of minimum salary. Subjects whose rankings were best predicted by salary standard deviation (center boxes) judged the low-mean, narrow-standard-deviation society as more fair than the high-mean, widestandard-deviation society. Subjects whose rankings were best described by minimum salary (lower boxes) did not have a consistent set of rankings. In sum, Figure 3 shows systematic differences in trade-offs across groups. Similar patterns were found for preference rankings.

\section{Effects of the work-salary correlation}

Experiment 2 investigates societies that vary in work-salary correlations as well as minimum salaries, salary means, and salary standard deviations. Table 5 presents the percentage of subjects whose fairness and preference rankings correlated highest with the four experimental factors. Approximately $75 \%$ of the subjects had fairness rankings that correlated highest with the work-salary correlation. The remaining $25 \%$ had rankings that were best described by minimum salary. Approximately $50 \%$ of the subjects had preference rankings that were best described by the correlation and the other $50 \%$ were best predicted by the minimum salary. Almost no subjects had fairness or preference rankings that were best predicted from measures of equality or efficiency.

Table 6 shows median correlations for best-fitting groups, as in Table 4 . Rankings of subjects in the correlation and minimum salary groups were correlated with all four experimental measures. Once again, correlations were highest for the best-fitting measures. The other correlations were lower, but not zero. These correlations ranged from .16 to .52 for fairness and .12 to .44 for preference. Salary mean and standard deviation also contribute 

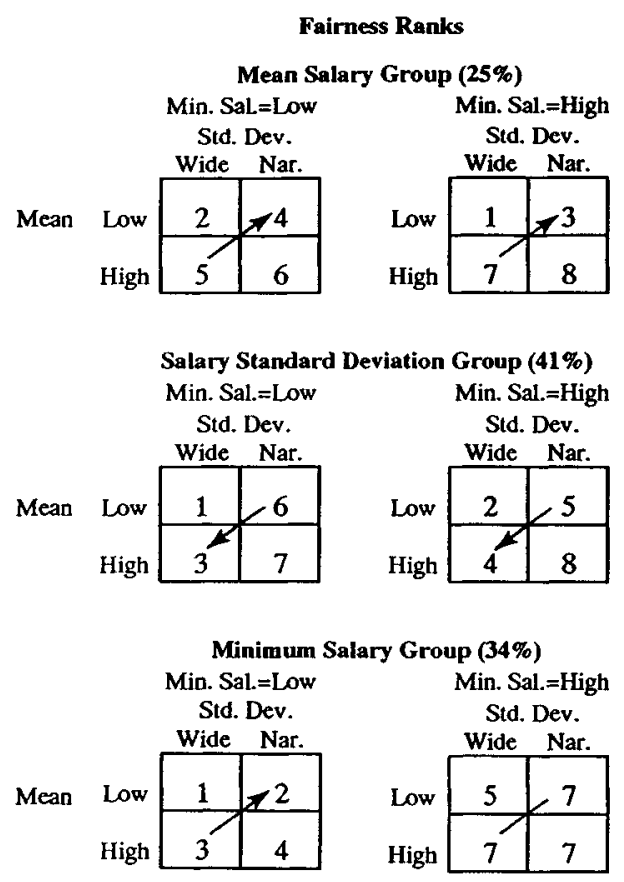

Figure 3 Median rankings of societies from Experiment 1 for each group of subjects best fit by an experimental measure. Upper boxes, center boxes, and lower boxes show mean salary, salary standard deviation, and minimum salary groups, respectively. Numbers range from 1 (least fair society) to 8 (most fair society).

Table 5 Percentage of subjects best fit by experimental measures

\begin{tabular}{lllll}
\hline \hline Response & Correlation & Minimum salary & Salary std. dev. & Mean salary \\
\hline Fairness & 74 & 26 & 0 & 0 \\
Preference & 50 & 44 & 0 & 6 \\
\hline \hline
\end{tabular}

to the predictability of fairness and preference rankings, although they are not the best predictors.

Figure 4 presents median fairness rankings for subjects in the correlation and minimum salary groups. Numbers range from 1 (least fair society) to 16 (most fair society). Within each box, rows are minimum salaries and columns are work-salary correlations. Different boxes reflect societies with different levels of salary mean and salary standard deviation. Once again, certain patterns are consistent across groups. Within a box, the lowcorrelation, low-minimum-salary society is always ranked lowest. The highcorrelation, high-minimum-salary society is always ranked highest. Subjects in the correlation group (upper boxes) judged the high-correlation, 
Table 6 Median correlations of subject rankings with experimental measures shown for subject groups

\begin{tabular}{|c|c|c|c|c|}
\hline \multirow[b]{2}{*}{ Measures } & \multicolumn{2}{|c|}{ Fairness groups } & \multicolumn{2}{|c|}{ Preference groups } \\
\hline & Correlation & $\begin{array}{l}\text { Minimum } \\
\text { salary }\end{array}$ & Correlation & $\begin{array}{l}\text { Minimum } \\
\text { salary }\end{array}$ \\
\hline Correlation & 0.87 & 0.40 & 0.80 & 0.35 \\
\hline $\begin{array}{l}\text { Minimum } \\
\text { salary }\end{array}$ & 0.25 & 0.77 & 0.44 & 0.75 \\
\hline $\begin{array}{l}\text { Salary } \\
\text { std. dev. }\end{array}$ & 0.16 & 0.19 & 0.12 & 0.12 \\
\hline Mean salary & 0.20 & 0.52 & 0.25 & 0.27 \\
\hline
\end{tabular}

Note: Mean salary and salary standard deviation groups are not presented because there were either none or very few subjects in these groups.

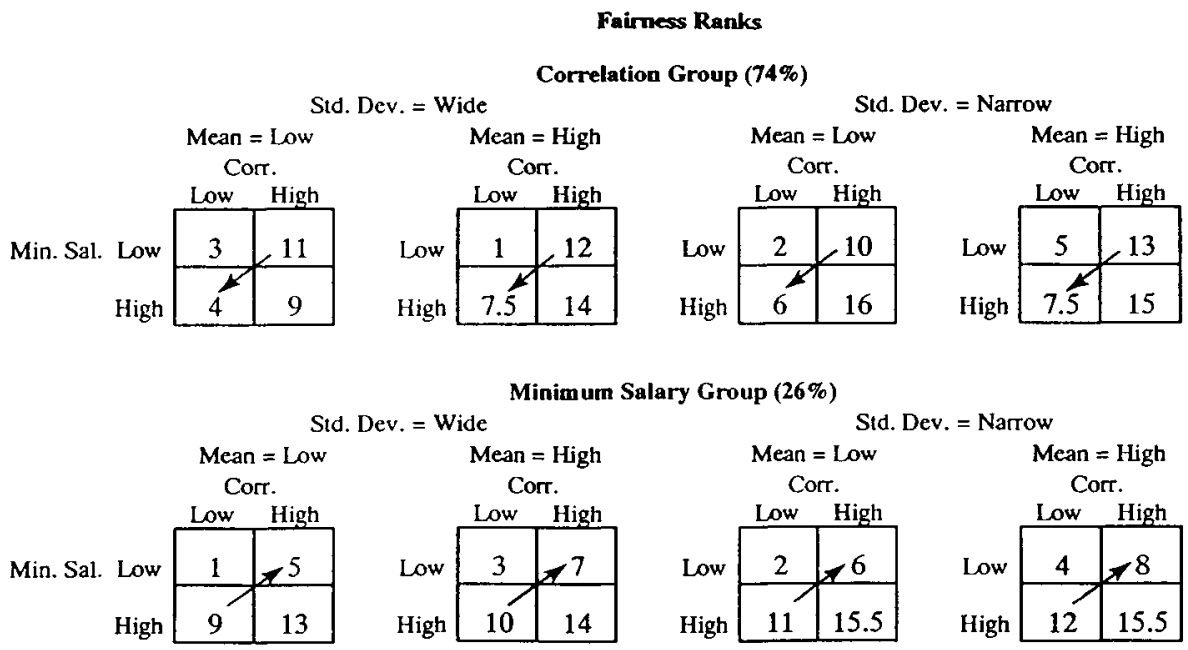

Figure 4 Median rankings of societies from Experiment 2 for subjects whose rankings were best fit by the correlation (upper boxes) and the minimum salary (lower boxes). Numbers range from 1 (least society) to 16 (most fair society).

low-minimum-salary society as more fair than the low-correlation, highminimum-salary society in all four boxes. Subjects in the minimum-salary group (lower boxes) showed the opposite pattern. Preference rankings were similar to fairness rankings.

\section{Discussion}

Results from these experiments suggest that many people make trade-offs when judging societal fairness and preference. When equality and effi- 
ciency are varied in conjunction with other factors, trade-offs tend to occur between minimum salary and work-salary correlation. These measures are better predictors of fairness and preference judgments. Approximately 75\% and $50 \%$ of the subjects had fairness and preference rankings that were best described by work-salary correlation, respectively. Virtually none of the subjects had fairness or preference rankings that were best predicted by equality and efficiency.

Why might people focus on the minimum salary and the work-salary correlation? Minimum salary might be viewed as a safety net beneath which people should not fall. The work-salary correlation may reflect the incentive system within the society. A high correlation implies that greater effort will lead to greater rewards. It also implies equal pay for equal work. But is societal fairness simply a high effort-reward correlation? Correlations could be high due to extreme outliers. Consider the salaries of some chief executive officers that are several hundred times more than those of the average workers. Effort-reward correlations could be low for most of the workers, but the overall correlation could be high due to a single point, the CEO. It would be interesting to investigate the extent to which societies with identical correlations but different outliers are judged fair.

As far back as Aristotle, justice has been thought to depend on the relationship between deservingness (effort, work, or productivity) and reward. Mellers (1982) examined fairness ratings of faculty members in hypothetical departments and found quite different deservingness functions between salary and merit in departments with the same salary-merit correlations. Deservingness functions were positively accelerated, linear, and negatively accelerated, depending on the joint distribution of salary and merit. Deservingness functions are not captured by correlations alone. However, in many situations, correlations may be a good first approximation. In fact, the correlation is a special case of Birnbaum's (1983) adjustment model of fair salaries. Birnbaum suggested that fair salaries might be determined by a context-dependent relationship between deservingness and reward. Salaries are assumed to be fair to the extent that they are determined by this relationship.

Results from these experiments also suggest that the societies in which people prefer to live are not necessarily judged as most fair. Many people judge societies with high correlations as fair, but they prefer to live in societies with high minimum salaries. Differences between fairness and preference judgments have also been found by Messick and Sentis (1979), who investigated judged allocations in situations where subjects assigned payments to themselves and another. In one condition, subjects divided rewards fairly, and in the other condition, they allocated rewards as they wished. Amounts that subjects preferred to give themselves were larger than amounts they judged to be fair.

What motivates societal preferences? One possibility is self-interest. People may be concerned about their own position in society. When their status 

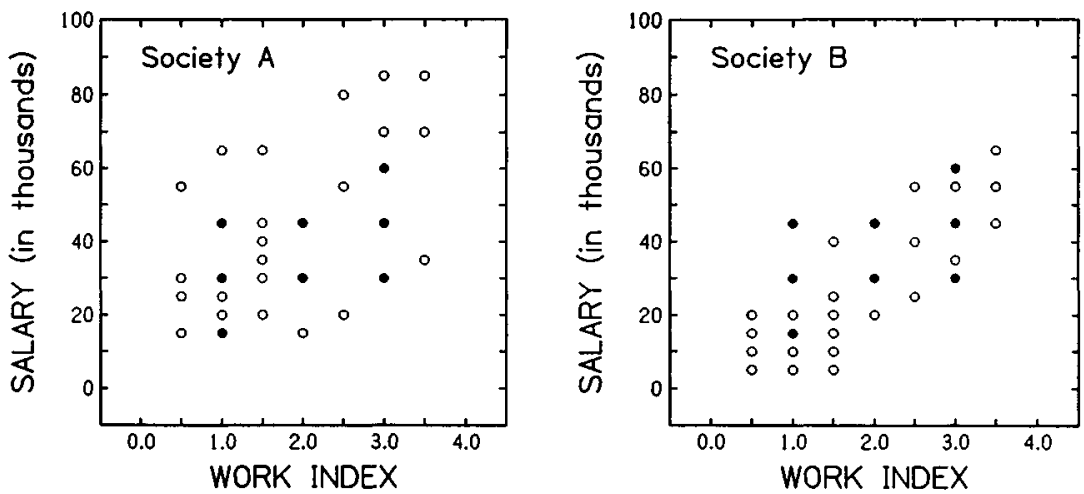

Figure 5 Two illustrative societies from Experiment 3. Common members (solid circles) are nested within different societies. Additional members (open circles) are varied across societies.

is uncertain, it may be prudent to prefer societies that help the least advantaged. Rawls develops this point in his theory of distributive justice. Another possibility is altruism. People may be genuinely concerned about the plight of the poor and prefer to live in societies that care for the needy. Research on social dilemmas indicates that some percentage of people act in altruistic ways, even when it entails personal sacrifice (Caporael, Dawes, Orbell, \& van de Kragt, 1989). See Tyler and Dawes (this book) for a further discussion of this topic.

\section{Micro fairness}

Experiment 3 examines whether factors that describe fairness judgments at the individual level resemble those at the societal level. Societies in Experiment 1 were constructed such that eight individuals (points in the scatterplots) were common to each society. Other points were added to manipulate the minimum salary, salary mean, and salary standard deviation. Figure 5 shows two illustrative societies. Solid points are the common members; open points are individuals who differ across societies. Society $\mathrm{A}$ has a high salary mean and a high minimum salary, but a wide salary standard deviation. Society B has a narrow salary standard deviation, but a low salary mean and low minimum salary.

Subjects were asked to rate the extent to which an individual was underbenefited or overbenefited on an 80 to -80 scale (where $80=$ very very overbenefited, $0=$ fairly treated, and $-80=$ very very underbenefited). As in the other experiments, they were told that the poverty level was $\$ 15,000$. Subjects were given eight societies and judged 15 randomly ordered individuals in each society (the eight solid points in each panel of Figure 5 and seven points that differed for each society). After completing the experimental trials, subjects answered the same questionnaire used in Experi- 


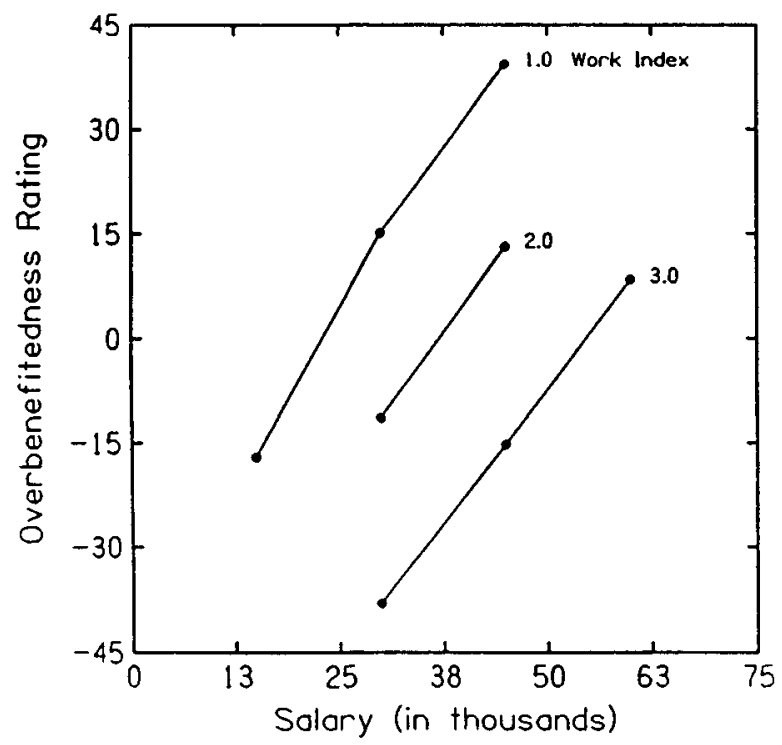

Figure 6 Mean overbenefited ratings for common members averaged over societies. Ratings are plotted against salary with a separate curve for each level of work.

ment 1. Participants were 88 undergraduates at the University of California at Berkeley who received credit in a lower division psychology course for their participation.

Figure 6 presents ratings for the eight common individuals, averaged over all eight societies. Judged overbenefitedness increased with salary and decreased with work index. Similar means were obtained for each society. Average ratings for the common individuals never changed sign across societies; an individual who appeared overbenefited in one society was never judged as underbenefited in another. But despite the fact that the signs did not change, the magnitudes of the ratings varied systematically across societies.

To illustrate the contextual effects, Table 7 presents average ratings of the common individuals in each of the eight societies. Common individuals were judged more overbenefited as mean salary, salary standard deviation, and minimum salary decreased. All three factors were statistically significant. ${ }^{4}$

Which factors accounted for more variance?

For each subject, eight ratings were computed, one for each society, by averaging responses for the common individuals. These ratings were correlated with three orthogonal rankings based on salary mean, salary standard deviation, and minimum salary. Table 8 shows that for the largest 
Table 7 Mean overbenefitedness ratings for common members in different societies

\begin{tabular}{llcllr}
\hline \hline & \multicolumn{2}{c}{$\begin{array}{c}\text { Low minimum } \\
\text { salary }\end{array}$} & & \multicolumn{2}{c}{$\begin{array}{c}\text { High minimum } \\
\text { salary }\end{array}$} \\
\cline { 2 - 3 } & \multicolumn{2}{c}{ Mean salary } & & & \multicolumn{2}{c}{ Mean salary } \\
\cline { 2 - 3 } Salary std. dev. & Low & High & & Low & High \\
\hline Wide & 0.51 & -3.53 & & 0.67 & -6.58 \\
Narrow & 5.76 & -1.92 & & 2.54 & -3.28 \\
\hline \hline
\end{tabular}

Note: Mean ratings are averaged over common members. The response scale ranged from -80 to 80 .

Table 8 Percentage of subjects best fit by experimental measures

\begin{tabular}{llll}
\hline \hline Response & Minimum salary & Salary std. dev. & Mean salary \\
\hline Rating & 23 & 32 & 45 \\
\hline \hline
\end{tabular}

percentage of subjects, overbenefitedness ratings correlated with salary mean, followed by salary standard deviation, and then minimum salary. Correlations were also computed for each common member in all eight societies, and results were similar to those based on averages; for the largest percentage of subjects, overbenefitedness correlated with decreases in salary mean.

\section{Discussion}

Experiments 1 and 3 allow a comparison of societal and individual fairness judgments. At the societal level, the largest percentage of subjects had fairness rankings that correlated highest with salary standard deviation. Minimum salary came in second, and salary mean took third place. At the individual level, the largest percentage of subjects had fairness rankings that correlated highest with salary mean. Salary standard deviation came in second place, followed by minimum salary.

Differences between individual and societal fairness might occur because people use different criteria to assess macro and micro justice. Subjects may make different trade-offs between equality and efficiency at different levels. If so, trade-offs could come into conflict; it may be impossible to make optimal trade-offs simultaneously. 


\section{Individual differences}

The present experiments demonstrate individual differences in fairness and preference judgments. Several studies have examined individual differences in fairness. In a review on sex and gender differences, Kahn and Gaeddert (1985) noted that men tend to endorse distributions of rewards in which ratios of outcomes to inputs are equal across individuals, whereas women tend to allocate rewards in a more uniform fashion. Major and Adams (1983) reported that women tend to have less variability than men in their reward allocations. Other studies have investigated individual differences in political ideology. Rasinski (1987) found that perceptions of fairness correlated with political orientation. Those scoring high on efficiency (proportionality rules for fair divisions) tended to be more conservative, whereas those scoring high on equality (egalitarian rules for fair divisions) tended to be more liberal.

Subjects in the present experiments were UC Berkeley undergraduates, and one might expect the vast majority to be liberal Democrats. However, only $60 \%$ of the subjects described themselves as Democrats. The average conservative/liberal rating was at the center of the scale. Roughly half were men, and half were women. The average self-report of socioeconomic status was 3.3 on a scale from 1 (lower class) to 5 (upper class).

Membership in a best-fitting group correlated significantly with the judged importance of that measure. However, group membership did not correlate significantly with demographic variables and political opinions, with a few notable exceptions. In Experiment 1, subjects with lower socioeconomic status tended to have fairness rankings that were best predicted by minimum salary. In Experiment 2, men tended to have preference rankings that were best predicted from the effort-reward correlation. Democrats, liberals, and women tended to have preference rankings that were best predicted from the minimum salary.

\section{Conclusions}

Results from the present experiments suggest that some people make tradeoffs between economic measures of equality and efficiency when judging societal fairness and preference. However, trade-offs tend to occur more often between the minimum salary and the work-salary correlation. These measures predict fairness and preference judgments to a greater extent than equality and efficiency. Furthermore, trade-offs tend to differ for fairness and preference judgments. The percentage of subjects best fit by minimum salary was greater for preference rankings than fairness rankings. Interestingly, preference rankings seemed more in line with Rawls's theory of justice than fairness rankings. Fairness rankings were not entirely consistent with Rawls's theory, egalitarianism, or utilitarianism.

Finally, factors that determine fairness at the individual level differ from 
those that describe fairness at the societal level. Micro and macrojustice can come into conflict whenever we think it is fair to treat individuals and groups differently. It may be one thing to vote for overall cuts in welfare programs, and another thing to refuse assistance to a homeless person who lost his job due to illness. Understanding the nature of these differences may ultimately help us reach more acceptable trade-offs between economic and psychological factors.

\section{References}

Abelson, R. P., \& Levi, A. (1985). Decision making and decision theory. In G. Lindzey and E. Aronson (Eds.), Handbook of social psychology (3rd ed.). New York: Random House.

Bentham, J. (1961/1789). Principles of morals and legislation. New York: Doubleday.

Birnbaum, M. H. (1983). Perceived equity of salary policies. Journal of Applied Psychology, 68, 49-59.

Brickman, P., Folger, R., Goode, E., \& Schul, Y. (1981). Microjustice and macrojustice. In M. J. Lerner and S. C. Lerner (Eds.), The justice motive in social behavior. New York: Plenum.

Caporael, L. R., Dawes, R. M., Orbell, J. M., \& van de Kragt, A. (1989). Selfishness examined: Cooperation in the absence of egoistic incentives. Behavioral and Brain Sciences, 12, 683-739.

Einhorn, H. J., \& Hogarth, R. M. (1981). Behavioral decision theory: Processes of judgment and choice. Annual Review of Psychology, 32, 53-88.

Hadari, S. A. (1988). Value trade-off. Journal of Politics, 50, 655-676.

Kahn, A. S., \& Gaeddert, W. P. (1985). From theories in equity to theories in justice: Deliberating consequences of studying women. in V. E. O'Leary, R. E. Unger, \& B. S. Wailston (Eds.), Women, gender, and social psychology. Hillsdale, NJ: Erlbaum.

Major, B., \& Adams, J. B. (1983). Role of gender, interpersonal orientation, and self-presentation in distributive-justice behavior. Journal of Personality and Social Psychology, 45, 598-608.

Mellers, B. A. (1982). Equity judgment: A revision of Aristotelian views. Journal of Experimental Psychology: General, 111, 242-270.

Messick, D. M., \& Sentis, K. P. (1979). Fairness and preference. Journal of Experimental Social Psychology, 15, 418-434.

Mitchell, G., Tetlock, P. E., Mellers, B. A., \& Ordónez, L. (1992). Judgments of social justice: Compromises between equality and efficiency. Unpublished manuscript.

Okun, A. (1975). Equality and efficiency: The big tradeoff. Washington, DC: Brookings Institute.

Rasinski, K. A. (1987). What's fair is fair - or is it? Value differences underlying public views about social justice. Journal of Personality and Social Psychology, $53,201-211$.

Rawls, J. (1971). A theory of justice. Cambridge, MA: Harvard University Press.

Tetlock, P. E. (1986). A value pluralism model of ideological reasoning. Journal of Personality and Social Psychology, 50, 819-827. 


\section{Notes}

1 Subjects were given pairs of societies and judged which society had: (1) a higher mean salary, (2) a larger salary variance, and (3) a higher correlation between salary and effort. All subjects properly detected differences in the manipulations.

2 Half of the subjects were presented with scatterplots showing the poverty line as a horizontal line, and half were not. There was no significant effect of poverty line, and all analyses were collapsed over the two groups.

3 These correlations are point-biserial correlations that cannot exceed .87.

4 All tests of significance were done at an alpha level of .01. 